\title{
Inflação de Alimentos no Brasil em Período da Pandemia da Covid 19, Continuidade e Mudanças
}

\author{
José Giacomo Baccarin ${ }^{1}$ e Jonatan Alexandre de Oliveira ${ }^{2}$
}

Desde 2007, os preços dos alimentos sobem mais intensamente do que o conjunto dos preços ao consumidor no Brasil. O objetivo do trabalho é comparar a inflação de alimentos no primeiro semestre de 2020 com a de 2007 e 2019, verificando se houve mudanças em suas características e razões. Usam-se informações do Instituto Brasileiro de Geografia e Estatística (IBGE) que permitem analisar o Índice de Preços ao Consumidor Amplo (IPCA) e seus componentes. Entre 2007 e 2019, preços da alimentação fora do domicílio expandiram-se mais que da alimentação no domićlio. Entre os componentes desta, os preços dos menos processados aumentaram mais do que os dos mais processados, indicando que a origem da inflação de alimentos foi agropecuária, com as carnes tendo grande contribuição para o fato. Por sua vez, no primeiro semestre de 2020, produtos sem comércio exterior significativo, feijão, arroz, frutas, legumes e verduras, pressionaram mais a inflação. Em todo o período, as condições de comércio exterior, preço internacional e taxa de câmbio, tiveram forte influência na inflação de alimentos. No primeiro semestre de 2020, entre as causas, ganhou relevância o aumento da demanda de alimentos nos supermercados, aparentemente não acompanhado pela expansão da oferta.

Palavras-chave: Iflação de alimentos; Comércio exterior; Preços ao consumidor.

\section{Food Inflation in Brazil in the Covid-19 Pandemic Period, Continuity and Changes}

Since 2007, food prices have risen more sharply than the set of consumer prices in Brazil. The objective of the work is to compare food inflation in the first half of 2020 with that of 2007 and 2019, checking if there have been changes in its characteristics and reasons. Information from the Instituto Brasileiro de Geografia e Estatística (IBGE) is used to analyze the Extended National Consumer Price Index (IPCA) at different levels of aggregation. Between 2007 and 2019, prices of food outside the home expanded more than that of food at home. Among the components of this, the prices of the least processed increased more than those of the most processed, indicating that the origin of food inflation was agricultural, with meat having a great contribution to the fact. In turn, in the first half of 2020, non-tradable products, beans, rice and fruits, vegetables and greens, were the ones that put the most pressure on inflation. Throughout the period, conditions of foreign trade, international price and exchange rate, had a strong influence on food inflation. In the first half of 2020, among the causes, increased demand for food in supermarkets gained relevance, apparently not accompanied by the expansion of supply.

1 Professor Livre Docente da Universidade Estadual Paulista "Júlio de Mesquita Filho", UNESP, Faculdade de Ciências Agrárias e Veterinárias/Campus de Jaboticabal. Departamento de Economia, Administração e Educação. Emdereço para Correspondência: Rodovia Prof. Paulo Donato Castellane, s/n.- Jaboticabal/SP - CEP 14884-900. Tel +55(16) 3209-7257. E-mail: jose.baccarin@unesp.br; ID ORCID: https://orcid.org/0000-0002-8120-3621.

2 Universidade Estadual Paulista “Júlio de Mesquita Filho", UNESP, Faculdade de Ciências Agrárias e Veterinárias/Campus de Jaboticabal. Doutor em Geografia. Bolsista DTI-A (CNPq). Email: jonatan.oliveira@unesp.br. ID ORCID: https://orcid.org/0000-0002-2326-5912 
Keywords: Food inflation; Foreign trade; Consumer prices.

\section{INTRODUÇÃO}

Uma observação inicial é que o preço ao consumidor dos alimentos sofre influência de acontecimentos nas várias etapas das cadeias agroalimentares, em especial da produção agrícola, transformação industrial e comércio varejista. Quando se fala de inflação de alimentos, ou seja, do fato destes produtos ficarem relativamente mais caros que outros bens e serviços, deve-se procurar identificar a origem deste comportamento, se agrícola, industrial ou dos serviços.

No Brasil, entre 2007 e 2019, houve manifestação da inflação de alimentos. Enquanto o Índice de Preços ao Consumidor Amplo (IPCA) crescia 103,5\%, um de seus nove grupos, o Índice de Preços de Alimentação e Bebidas (IPAB), expandiase em 155,7\%. Sob os efeitos da Pandemia Covid 19, tal fato continuou a se registrar, com o IPCA praticamente ficando estável nos primeiros seis meses de 2020 , elevando-se em $0,1 \%$, contra $4,1 \%$ do IPAB ${ }^{[1]}$.

Em termos sociais, a inflação de alimentos atinge mais intensamente a população com menor renda, cujo dispêndio com alimentação é relativamente mais alto que o de outras camadas sociais. Em consequência, pode ocorrer diminuição da quantidade de alimentos adquirida ou a substituição daqueles com maior pelos com menor qualidade nutricional, agravando a situação de Insegurança Alimentar e Nutricional. Tal fato é ainda mais preocupante em períodos como o atual, da crise sanitária e econômica decorrente da Covid 19, em que o acesso aos alimentos sofre constrangimento em decorrência do aumento da desocupação (desemprego) e da queda da renda média da população.

Ao mesmo tempo, como destacam Graziano da Silva e Tavares ${ }^{[2]}$, a alta dos preços dos alimentos pode servir de estímulo, após certo tempo, ao aumento da oferta de suas matérias primas agrícolas. Nesta direção, os autores recomendam a adoção de políticas públicas que estimulem a produção agrícola com finalidade alimentícia, em especial por agricultores familiares, com reflexos positivos em suas rendas. Para os consumidores mais pobres das cidades, maior oferta de alimentos serviria como um fator de contenção da inflação de alimentos, melhorando a situação de Segurança Alimentar e Nutricional (SAN).

O objetivo deste trabalho é comparar a inflação de alimentos no Brasil no primeiro semestre de 2020 com a registrada entre 2007 e 2019, verificando se houve mudanças em suas características e razões. Este melhor entendimento da inflação de alimentos brasileira abre espaço para proposição de políticas públicas mais adequadas nos campos da disponibilidade e do acesso aos alimentos.

$\mathrm{Na}$ segunda seção, de caráter metodológico, abordam-se a fonte e o tratamento dos dados usados. A terceira é dedicada a discutir o acontecido entre 2007 e 2019, enquanto na quarta debate-se o ocorrido no primeiro semestre de 2020. A quinta seção traz algumas considerações finais.

Pelos fatos serem muito recentes, entendese que as análises de 2020 devem ser consideradas com cuidados adicionais. Outra questão a ser levada em conta é a grande diferença dos tempos analisados, 13 anos e 1 semestre, com o primeiro permitindo definir uma tendência de longo prazo e o segundo apenas uma variação conjuntural.

\section{INFORMAÇÕES METODOLÓGICAS}

Os dados sobre variação de preços e composição de consumo no Brasil podem ser obtidos no Sistema Nacional de Índices de Preços ao Consumidor (SNIPC), a cargo do Instituto Brasileiro de Geografia e Estatístical ${ }^{[1,3,4]}$, que fornece diferentes índices de preço ao consumidor. Um deles, o índice 
oficial de inflação do Brasil, é o IPCA, com a seguinte população-objetivo: "famílias residentes nas áreas urbanas das regiões de abrangência do SNIPC com rendimentos de 1 a 40 salários mínimos, qualquer que seja a fonte dos rendimentos" [3].

Os bens e serviços do IPCA são divididos em quatro níveis de hierarquia: grupos, subgrupos, itens e subitens. A cada um é atribuído um coeficiente de ponderação, resultado da razão entre o valor de seu gasto e o total das despesas do consumidor com todos os bens e serviços. A base para o estabelecimento dessas ponderações são as edições da Pesquisa de Orçamento Familiar (POF), feitas pelo IBGE. O IPCA de 2007 e 2011 se baseou na POF 2002-2003, de 2012 a 2019, na de 2008-2009 e, em 2020, vem se usando a de 2017-2018.

Os grupos de despesas considerados são nove: alimentação e bebidas, habitação, artigos de residência, vestuário, transportes, saúde e cuidados pessoais, despesas pessoais, educação e comunicação. Alimentação e bebidas é subdividido em dois subgrupos: alimentação no domicílio e alimentação fora do domicílio. Normalmente, os gastos com a alimentação no domicílio representam próximo ao dobro daqueles fora do domicílio. Por exemplo, com base na POF 2008-2009, o grupo alimentação e bebidas representava $22,1 \%$ da estrutura de ponderação do IPCA, 7,1\% do subgrupo alimentação fora do domicílio e $15,0 \%$ da alimentação no domicílio[4].

O subgrupo alimentação no domicílio contém 16 itens: cereais, leguminosas e oleaginosas; farinhas, féculas e massas; tubérculos, raízes e legumes; açúcares e derivados; hortaliças e verduras; frutas; carnes; pescados; carnes e peixes industrializados; aves e ovos; leite e derivados; panificados; óleos e gorduras; bebidas e infusões; enlatados e conservas e; sal e condimentos. Seus subitens, cujo número ultrapassa uma centena, apresentaram variação, com eliminação de alguns e inclusão de outros, de acordo com mudanças no padrão de consumo observadas nas POF citadas.

Por sua vez, alimentação fora do domicílio não contempla itens e, em 2020, contém nove subitens: refeição; lanche; refrigerante e água mineral; cafezinho; cerveja; outras bebidas alcóolicas; vinho; doces e; sorvete.
Mensalmente, o IBGE faz pesquisa de preços em 13 cidades (capitais) ou regiões metropolitanas, obtendo a variação em relação ao mês anterior de preços dos subitens. Através da estrutura de ponderação, calcula-se a variação média de itens, subgrupos, grupos e, finalmente, do IPCA. Também se leva em conta a participação de cada cidade ou região metropolitana no seu conjunto, de forma que o IPCA nacional é uma média ponderada da variação de preços dessas localidades.

Os principais resultados do artigo baseiamse na análise de duas variáveis, a variação de preços e a contribuição dos componentes (subgrupos, itens e subitens) para a inflação do grupo alimentação e bebidas. Neste caso, leva-se em conta também a importância relativa de cada componente na estrutura de ponderação do IPCA.

\section{MANIFESTAÇÃO E RAZÕES DA INFLAÇÃO DE ALIMENTOS, DE 2007 A 2019}

Vários estudos mostram que, seguindo tendência internacional apontada pela Organização das Nações Unidas para Alimentação e Agricultura $(\mathrm{FAO})^{[5]}$, os alimentos no Brasil ficaram relativamente mais baratos nas últimas quatro décadas do século XX[6,7,8]. Farina e Nunes ${ }^{[8]}$ calcularam queda real de $20 \%$ no preço da alimentação como um todo e $15 \%$ para a alimentação fora do lar, entre agosto de 1994 e fevereiro de 2002. Ademais, consideraram que ganhos de produtividade e redução de margens na indústria de alimentação e distribuição de alimentos (com destaque à ação dos supermercados no varejo) tiveram importância mais decisiva do que a agricultura na redução dos preços dos alimentos.

Nos primeiros anos do presente século, de 2001 a 2006, o IPCA registrou acréscimo de 55,3\% e o IPAB, valor pouco menor, de $50,9 \%{ }^{[1]}$. Ou seja, o fenômeno da inflação de alimentos continuou não se constatando.

Entretanto, a situação, a partir de 2007, temse mostrado diferente, como ilustra o Gráfico 1 . O padrão, observado em 11 anos, foi o de aumento do IPAB acima do IPCA, ocorrendo o contrário em 
apenas dois anos, 2009 e 2017, exceções estas explicadas adiante.

Gráfico 1. Variação anual do IPCA e do IPAB, 2007 a 2019, Brasil.

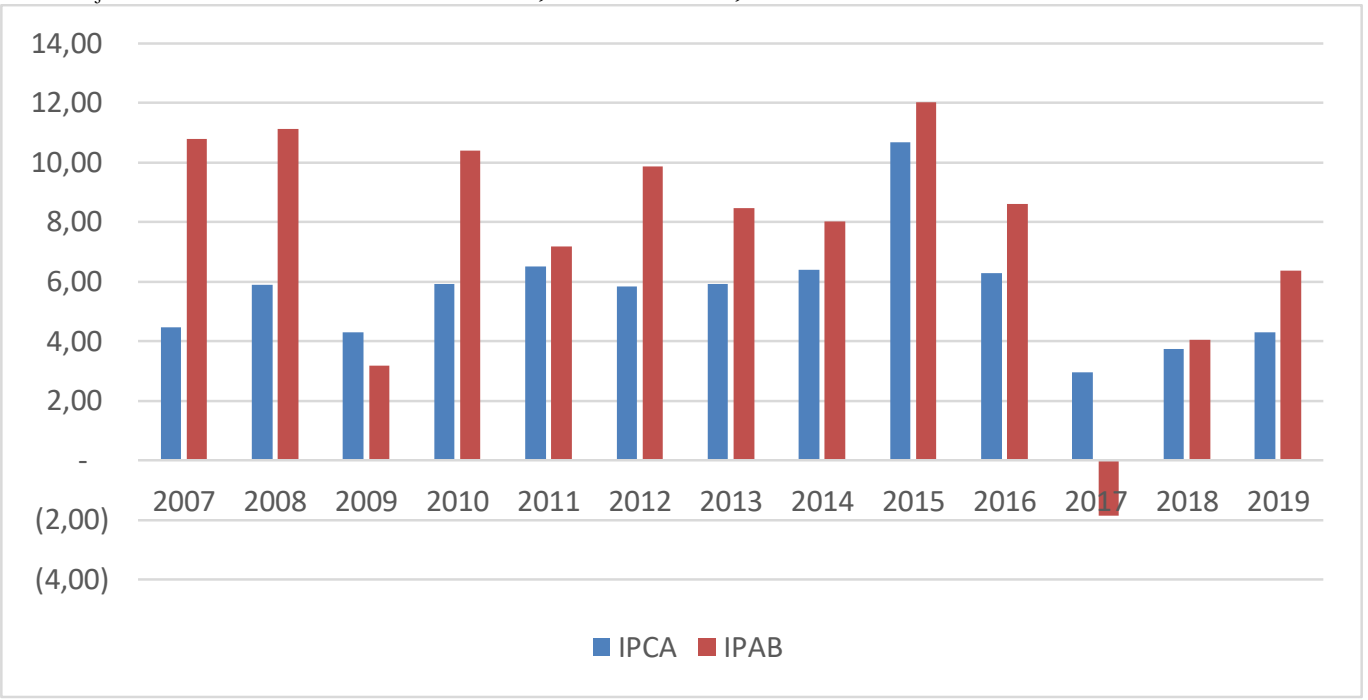

Fonte: IBGE (2020) ${ }^{[1]}$.

$\mathrm{Na}$ tentativa de entender o aumento do preço real dos alimentos no Brasil, após 2007, podese levantar algumas hipóteses. No subperíodo $2007-$ 2014 verificou-se forte queda da taxa de desocupação e aumento da renda média real dos ocupados no Brasil[9]. Isto mais o crescimento de programas sociais, como o Programa Bolsa Família e aumento real do salário mínimo, trouxe expansão na demanda por alimentos, o que poderia pressionar seus preços para cima.

Contudo, deve-se considerar que a reposta do consumo de alimentos à variação da renda tem se revelado pequena. Assim, estudo de Hoffmann ${ }^{[10]}$ sobre a elasticidade-renda (ER) com dos gastos com alimentação e bebidas no Brasil mostra que seu valor era de 0,538, em 2008/09, bem menor que a outros tipos de gastos, como habitação, transporte, educação e saúde e cuidados pessoais. Especificamente, a ER da alimentação no domicílio foi de 0,407 e de fora do domicílio, 0,828[10]. Por ter um componente de lazer (ou de menor essencialidade física), a alimentação fora do domicílio é relativamente mais afetada pela variação da renda dos consumidores brasileiros, embora tenha participação menos significativa em seus gastos, como já visto.
Alternativamente, poder-se-ia imaginar que a produção agrícola brasileira destinada à alimentação tenha se mostrado insuficiente, estimulando aumento dos preços recebidos pelos produtores, que acabam por serem transferidos aos consumidores. De maneira geral, os números apontam para o sentido inverso, ou seja, crescimento vigoroso de produção, como no caso dos grãos ${ }^{[1]}$ e dos principais produtos pecuários ${ }^{12]}$. Contudo, pode ter acontecido que alguns produtos, como arroz, feijão e frutas, legumes e verduras (FLV), tiveram desempenho produtivo deficiente, resultando em pressões inflacionárias mais localizadas.

A explicação geral que se propõe neste estudo para a inflação de alimentos no Brasil, de 2007 a 2019, é que ela não teve origem nos segmentos industriais e de serviços (varejo, em especial), mas sim nas condições prevalecentes nos mercados agrícolas, que, por sua vez, sofreram fortes efeitos dos preços internacionais e da taxa de câmbio. Acontece que, desde 1990, vem se observando aumento da participação brasileira nas exportações mundiais e da parcela de produção agrícola nacional destinada às exportações ${ }^{[13,14]}$. Como mostram os dados do Ministério da Agricultura, Pecuária e Abastecimento (MAPA)[15], em várias cadeias agroalimentares, têm-se observado crescimento das 
exportações e do saldo comercial brasileiro, como nas carnes de boi, frango e suíno, açúcar, soja e derivados, suco de laranja e milho.

Nestes casos, as variações dos preços recebidos pelos exportadores, em dólares, tendem a ser transmitidas aos preços internos, em reais, o que pode ser acentuado ou amenizado pela variação da taxa de câmbio. Em outras cadeias, como no trigo e lácteos, o Brasil tem-se mostrado um importador líquido, também recebendo impactos das variações nas cotações internacionais.

Estudo do Instituto de Pesquisa Econômica Aplicada (IPEA) ${ }^{[16]}$ aponta a alta internacional dos preços das commodities como principal motivo para aumento de preços de alimentação e bebidas no Brasil. O estudo desdobra alimentos e bebidas em três subgrupos: a) comercializáveis no domicílio, que apresentam exportação significativa em relação à produção interna ou importação significativa em reação ao consumo interno; b) não comercializáveis no domicílio, com exportação ou importação pouco expressiva; c) não comercializáveis fora do domicílio, cujo consumo é muito afetado pela variação da renda do consumidor. Entre 2007 e maio de 2011, os preços do primeiro e terceiro subgrupos pressionaram para cima a inflação, enquanto os do segundo subgrupo puxaram-na para baixo, embora com flutuações bem mais intensas que as dos outros subgrupos.

Em primeira aproximação, pode-se trabalhar com a concepção de que os preços internacionais afetam os preços internos apenas dos produtos agrícolas comercializáveis, enquanto os não comercializáveis seriam mais atingidos pelas condições de oferta interna. Contudo, ainda que indiretamente, este grupo pode ter seus preços afetados pelas condições internacionais. Não se deve esquecer que as diversas atividades agrícolas concorrem por terra e pelos investimentos e gastos dos agricultores, podendo-se supor que um aumento (diminuição) das cotações internacionais acabe afetando negativamente (positivamente) a área e produção dos não comercializáveis.

Ademais, pelo lado da demanda, é possível considerar que aumento de preços de produtos comercializáveis possa acarretar elevação de preços e, em seguida, de produção, em produtos não comercializáveis, mas que sejam substitutos dos primeiros. “(...) acrescente-se a possibilidade de transferência indireta a produtos substitutos, de modo que podem ser afetados bens não transáveis, por exemplo, a alta do preço do arroz levando a um maior consumo e alta de preço da batata" [17].

Em suma, mesmo os produtos com mercado externo pouco significativo podem ter seus preços internos afetados, ainda que indiretamente, pelas variações nas cotações internacionais dos comercializáveis.

O Gráfico 2 registra a variação dos preços internacionais de alimentos e da taxa de câmbio no presente século. Observa-se que, de 2000 a 2011, o Índice de Preços de Alimentos da FAO aumentou em mais de 50\% no mundo, para depois registrar uma tendência de queda suave, contudo, sem voltar ao patamar do início do século. Por sua vez, a moeda brasileira apresentou movimento inicial de desvalorização, seguida de valorização, entre 2003 e 2011, e forte desvalorização, a partir de então. 
Gráfico 2. Índice Internacional de Preços de Alimentos da FAO e de Taxa de Câmbio (R\$/US\$), 2000-19.

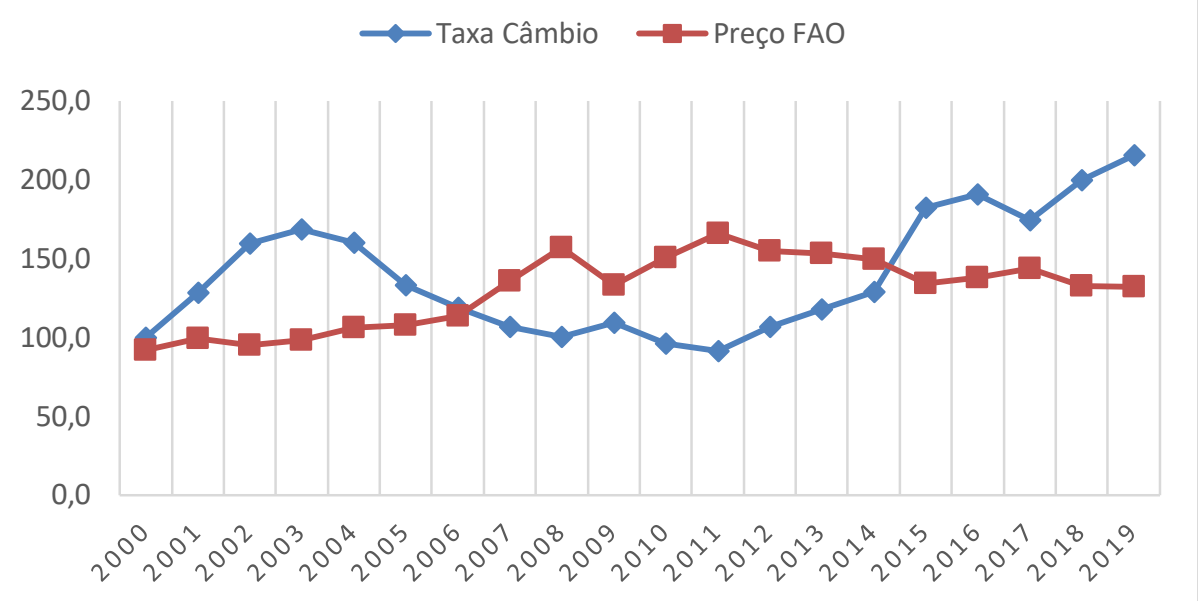

Fonte: FAO (2020)[5], IPEA (2020) ${ }^{[18]}$.

De 2007 a 2011, aparentemente, a elevação das cotações internacionais teve efeito mais significativo do que a valorização cambial, de forma que o resultado líquido foi o de elevação dos preços internos de alimentos no Brasil. A exceção foi 2009, em que os preços internacionais, temporariamente, caíram. Inversamente, de 2012 a 2019, a diminuição suave dos preços internacionais não foi suficiente para compensar a forte desvalorização do real, daí derivando pressões inflacionárias nos alimentos. Neste caso, a exceção foi 2017, em que a desvalorização do real foi, pontualmente, revertida.

Maior detalhamento da inflação de alimentos no Brasil pode contribuir para compressão de razões mais específicas e localizadas do fenômeno. Neste sentido, uma primeira comparação pode ser feita entre preços dos alimentos no domićlio e fora dele. Foi visto que o IPAB se elevou em 155,7\%, de 2007-2019. Ao mesmo tempo, o índice do subgrupo alimentação fora do domicílio se elevava em 174,4\% e o de alimentação no domicílio (IAD), 146,1\%[1]. A ER mais alta e a maior incidência dos serviços no custo explicam a inflação maior da alimentação fora do domićlio, em período em que, pelo menos até 2014, houve ganhos reais de renda e queda na desocupação no Brasil.

A Tabela 1 revela que cinco itens da alimentação no domićlio tiveram variação de preços acima do IAD, oito entre o IPCA e o IAD e apenas três tiveram variação inferior ao IPCA. Isso aponta que a pressão sobre o IPCA foi generalizada entre os itens do IAD, com exceção de óleos e gorduras, açúcares e derivados e enlatados e conservas.

Tabela 1. Variação de preços de itens da alimentação no domicílio do IPCA, em ordem decrescente, 2007 a 2019 , Brasil.

\begin{tabular}{lclc}
\hline \multicolumn{1}{c}{ Componente } & Variação & \multicolumn{1}{c}{ Componente } & Variação \\
\hline Carnes & 273,93 & Carnes e peixes industrializados & 125,47 \\
Hortaliças e verduras & 186,40 & Leites e Derivados & 125,33 \\
Tubérculos, raízes e legumes & 184,81 & Cereais, leguminosas e oleaginosas & 122,48 \\
Frutas & 175,18 & Bebidas e infusões & 117,48 \\
Pescados & 147,49 & Farinhas, féculas e massas & 114,49 \\
Alimentação no domicílio & 146,08 & IPCA & 103,46 \\
Aves e ovos & 133,92 & Óleos e gorduras & 87,44 \\
Sal e condimentos & 133,01 & Açúcares e derivados & 86,12 \\
Panificados & 126,08 & Enlatados e conservas & 85,33 \\
\hline
\end{tabular}

Fonte: IBGE, (2020) ${ }^{[1]}$. 
Considerando-se também a participação na estrutura de ponderação do IPCA, pode-se calcular que o item carnes contribuiu com $29,5 \%$ do IAD, os panificados com 10,3\% e leite e derivados com $10,2 \%$. Em conjunto, estes três itens foram responsáveis por, praticamente, $50 \%$ do IAD, entre 2007 e 2019.
Outro exercício é a associação dos diversos subitens dos alimentos no domicílio às atividades agrícolas que lhes dão origem. As dez cadeias relacionadas na Tabela 2 foram responsáveis por mais de $75 \%$ do IAD no Brasil. Duas, arroz e soja, apresentaram variação de preços abaixo do IPCA, cinco, trigo, bovinocultura de leite, avicultura de corte, suinocultura e tomate, entre o IPCA e o IAD e, acima deste último situaram-se três cadeias, bovinocultura de corte, feijão e banana.

Tabela 2. Dez cadeias agropecuárias com conjunto de subitens com maior contribuição para o IAD, em ordem decrescente, 2007 a 2019, Brasil.

\begin{tabular}{lcccc}
\hline \multicolumn{1}{c}{ Cadeia Agropecuária } & \% IPCA & $\begin{array}{c}\text { Contribuição } \\
\text { Ponderada }\end{array}$ & $\begin{array}{c}\text { Contribuição } \\
\text { Acumulada }\end{array}$ & Variação Média* \\
\hline Bovinocultura de corte & 2,34 & 30,62 & 30,62 & 286,73 \\
Trigo & 2,36 & 13,09 & 43,71 & 129,01 \\
Bovinocultura de leite & 1,84 & 10,53 & 54,24 & 126,39 \\
Avicultura de corte & 0,88 & 4,83 & 59,07 & 119,38 \\
Suinocultura & 0,84 & 4,73 & 63,80 & 115,32 \\
Feijão & 0,40 & 3,64 & 67,44 & 200,86 \\
Arroz & 0,70 & 2,82 & 70,25 & 87,49 \\
Tomate & 0,38 & 2,39 & 72,65 & 141,62 \\
Banana & 0,17 & 2,01 & 74,66 & 177,88 \\
Soja & 0,25 & 1,95 & 76,61 & 91,42 \\
\hline
\end{tabular}

Fonte: IBGE, (2020)[1]. *Ponderada pela importância dos subitens na cadeia.

Entre os comercializáveis, a cadeia da soja apresentou uma variação média de preços de seus produtos relativamente pequena, de $91,42 \%$, bem menor do que o IPAB. Algo semelhante aconteceu com a cadeia da cana-de-açúcar, não relacionada na Tabela 5, cujos produtos (açúcar cristal e refinado) têm participação de $0,34 \%$ no IPCA, mas apresentaram baixa variação média de preços, de $71,18 \%$.

Por sua vez, entre os não comercializáveis da Tabela 2, os subitens do feijão e banana apresentaram variação de preços bem acima do IAD e os do tomate, pouco abaixo, ainda que acima do IPCA.

Outro ponto que chama a atenção na Tabela 2, diz respeito a pressão altista de preços exercida pelas atividades pecuárias, que ocuparam quatro das cinco primeiras posições da tabela. A explicação geral é que tanto as carnes quanto os lácteos têm grande participação na estrutura de ponderação do IPCA. No caso da bovinocultura de corte, a pressão inflacionária daí derivada $(30,62 \%$ do total) resultou também da forte variação média dos preços de seus subitens, de $286,73 \%$, bem acima do IPAB.

Os produtos da cadeia do trigo foram responsáveis por 13,09\% da IAD no Brasil, ou seja, a segunda posição. Mais do que a variação média de seus preços, isto esteve mais relacionado com a alta participação dos derivados do trigo na estrutura do IPCA. Entre os nove subitens aí considerados, os três com maior importância no consumo são o pão francês, com participação no IPCA de 1,02\%, o macarrão, $0,30 \%$ no IPCA, e o biscoito, $0,50 \%$ do IPCA. Suas variações de preços, entre 2007 e 2019, foram, respectivamente, $153,07 \%, 106,17 \%$ e $80,34 \%$, apontando que produtos com processamentos mais sofisticados sofreram menores altas de preço.

$\mathrm{Na}$ bovinocultura de leite, que contribuiu com $10,53 \%$ do IAD, foram elencados sete subitens. Quatro deles tinham maior importância no consumo: leite fluido, queijo, iogurte e leite em pó, com 
participações respectivas no IPCA de $0,89 \%, 0,48 \%$, $0,23 \%$ e $0,20 \%$ e variações respectivas de preços de $126,86 \%, 122,42 \%, 82,46 \%$ e $156,93 \%$. Os dois mais importantes, portanto, tiveram variação de preços abaixo do IAD, mas acima do IPCA, enquanto o terceiro teve baixa variação de preço, bem menor que o IPCA. Por sua vez, o leite em pó destoou de casos anteriores, em que produtos com maior grau de processamento tiveram variações de preços relativamente mais baixas. Uma provável explicação é o alto volume de importação de leite em pó que, em 2018, por exemplo, representou 56\% dos US\$ 485 milhões de importação de lácteos pelo Brasil[15].

A avicultura de corte contribuiu com 4,83\% do IAD, fato que está mais associado a grande participação de seus dois subitens na estrutura do IPCA, de 0,88\%. Em termos de preços, o frango inteiro registrou uma variação de $127,13 \%$ e o em pedaço, de 108,98\%, bem menores que a dos produtos da bovinocultura de corte e pouco acima aos da suinocultura. Esta aparece logo em seguida, com participação de 4,63\% no IAD. A carne de porco subiu $162,72 \%$ e seus principais derivados subiram menos, $108,19 \%$ a linguiça e $87,75 \%$ o presunto.

Das cinco cadeias tratadas até agora, em três a exportações de seus produtos são muito importantes, bovinocultura de corte, avicultura de corte e suinocultura e duas apresentam alta dependência de importação, trigo e bovinocultura de leite. Contudo, antes de se associar suas pressões inflacionárias apenas ao fato de serem comercializáveis, deve-se levar em conta a sua alta participação nos gastos dos consumidores brasileiros.

As quatro cadeias seguintes, feijão, arroz, tomate e banana, têm comércio exterior e participação nos gastos dos consumidores bem menos significativos. O feijão e a banana se destacam por apresentarem a segunda e terceira variação de preços entre as cadeias da Tabela 2, atrás da bovinocultura de corte. No caso do tomate, seu aumento médio de preço, de $141,62 \%$, subestima o aumento do preço do tomate in natura, de 156,00\%, enquanto o atomatado teve aumento bem menor, de $109,91 \%$.

Outra inferência que se pode fazer, considerando o ocorrido em todas as cadeias, é que as evidências aqui levantadas apontam que produtos in natura ou baixo grau de processamento tiveram maior influência no IAD do que os com médio ou alto grau de processamento. Isso indica que as condições da agricultura foram mais importantes que as da indústria e, provavelmente, da distribuição no atacado e varejo para explicar a inflação de alimentos no Brasil, entre 2007 e 2019.

Isto já tinha se evidenciado em estudo anterior, relativo a 2007-14. Neste período, os alimentos com médio grau de processamento tiveram seus preços se elevando em $65,69 \%$ e os de alto, em $72,07 \%$. Ao mesmo tempo, os produtos com grau de processamento mínimo apresentaram elevação de preços de $111,19 \%$ e os in natura, de $117,54 \%{ }^{[19]}$.

\section{CONTINUIDADE E MUDANÇAS NA INFLAÇÃO DE ALIMENTOS EM 2020}

Uma publicação recente da CEPAL/FAO[20] analisa vários aspectos relacionados ao acesso aos alimentos na América Latina e Caribe. O Gráfico 3 mostra que, a partir de 2014, começou a diminuir o PIB per capita da região e aumentar a porcentagem de pessoas vivendo em extrema pobreza. Tais fatos apresentam tendência de se agravar, fortemente, em 2020. 
Gráfico 3. Produto Interno Bruto per capita (US\$) e porcentagem de pessoas em extrema pobreza, América Latina, 2001 a 2020.

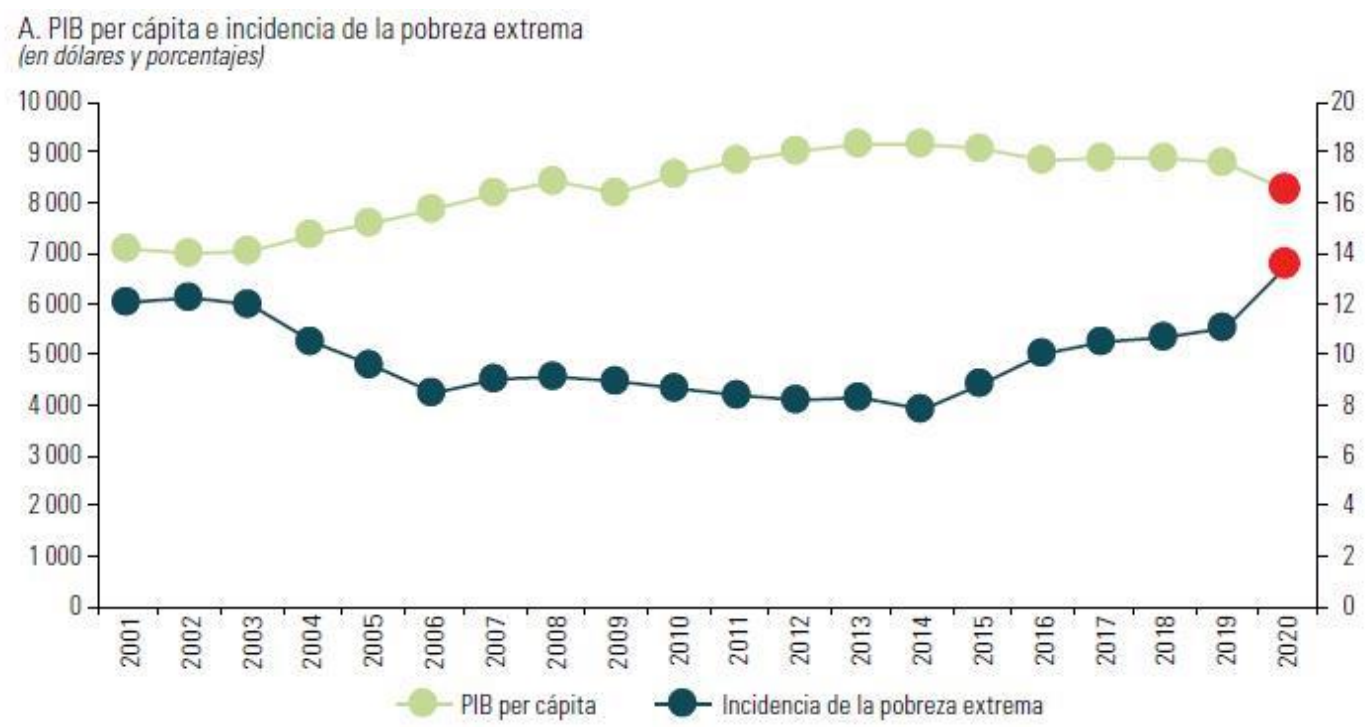

Fonte: CEPAL/FAO (2020)[20].

Em relação ao mundo todo, a América Latina e Caribe apresenta um complicador, qual seja, entre janeiro e maio de 2020 , o preço dos alimentos elevou-se em 3,3\% na região, enquanto caía 9,1\% globalmente ${ }^{[20]}$. Ou seja, os caribenhos e latinoamericanos estão convivendo com queda da renda média, aumento da pobreza e inflação de alimentos. Muito provavelmente, isto resultará em deterioração dos indicadores de SAN desta população, em 2020.

Convém fazer uma observação antes de se analisar os dados específicos do Brasil. Houve mudança na estrutura de ponderação do IPCA em
2020, de acordo com os resultados da POF 2017-18. No caso dos alimentos e bebidas, o IPAB passou a representar 19,35\% do IPCA, $13,48 \%$ do IAD e $5,87 \%$ dos alimentos fora do domicílio. Posto isto, a Tabela 3 revela que todos os grupos componentes do IPCA, com exceção de dois, apresentaram variação negativa ou muito baixa em seus preços no primeiro semestre de 2020. A educação foi uma exceção, marcada pelos reajustes das mensalidades escolares. Outra exceção foi o grupo alimentação e bebidas, cujos preços elevaram-se em 4,09\%, contra $0,10 \%$ do IPCA.

Tabela 3. Variação do IPCA e seus grupos, Brasil, janeiro a junho de 2020.

\begin{tabular}{lclc}
\hline \multicolumn{1}{c}{ Grupos do IPCA } & Variação \% & \multicolumn{1}{c}{ Grupos do IPCA } & Variação \% \\
\hline Alimentação e bebidas & 4,09 & Saúde e cuidados pessoais & 0,65 \\
Habitação & $-0,04$ & Despesas pessoais & 0,20 \\
Artigos de residência & $-0,74$ & Educação & 4,54 \\
Vestuário & $-1,94$ & Comunicação & 1,15 \\
\cline { 2 - 3 } Transportes & $-4,99$ & IPCA & 0,10 \\
\hline
\end{tabular}

Fonte: IBGE (2020) [1]

Entre os subgrupos da alimentação e bebidas, diferentemente do que se observara entre 2007 e 2019, a alimentação no domicílio apresentou variação maior de preços, de $4,75 \%$, no primeiro semestre de 2020, contra 2,59\% na alimentação fora do domicílio[1]. Isto é explicado pela restrição que a
Covid 19 impôs ao funcionamento de hotéis, restaurantes, bares e lanchonetes, cuja demanda despencou, fato que pode ser confirmado pela grande queda de seu pessoal ocupado. Por sua vez, a procura e as vendas de alimentos nos supermercados cresceram no primeiro semestre de 2020, o mesmo ocorrendo em seu nível de ocupação[21]. 
A Tabela 4 revela que todos os itens da alimentação no domicílio apresentaram variação de preços acima do IPCA, com exceção de carnes, que mostrou comportamento muito favorável ao consumidor, em decorrência da queda generalizada de preços da carne de vaca, porco e carneiro. Por sua vez, as outras fontes de proteína animal, pescados, aves e ovos e leites e derivados, apresentaram alto crescimento de preços, acima dos da alimentação no domicílio.

Tabela 4. Variação de preços de itens da alimentação no domicílio do IPCA, em ordem decrescente, Brasil, janeiro a junho de 2020.

\begin{tabular}{lclc}
\hline \multicolumn{1}{c}{ Componente } & Variação & \multicolumn{1}{c}{ Componente } & Variação \\
\hline Tubérculos, raízes e legumes & 49,87 & Pescados & 4,92 \\
Cereais, leguminosas, oleaginosas & 17,33 & Alimentação no domicílio & 4,75 \\
Hortaliças e verduras & 14,94 & Enlatados e conservas & 3,58 \\
Sal e Condimentos & 14,57 & Açúcares e derivados & 3,55 \\
Frutas & 8,97 & Bebidas e infusões & 2,72 \\
Leites e derivados & 6,33 & Carnes e Peixes Industrializados & 2,63 \\
Óleos e gorduras & 5,60 & Panificados & 2,04 \\
Aves e ovos & 5,09 & IPCA & 0,10 \\
Farinhas, féculas e massas & 4,96 & Carnes & $-8,43$ \\
\hline
\end{tabular}

Fonte: IBGE (2020) ${ }^{[1]}$.

No caso de sal e condimentos, o subitem responsável pela sua grande variação foi o alho, cujo preço aumentou em 38,51\% no período. Posto isto, pode-se dizer que foram os itens compostos por produtos in natura ou minimamente processados, tubérculos, raízes e legumes; cereais, leguminosas e oleaginosas; hortaliças e verduras; frutas, além do alho, os que apresentaram maior elevação de preços, próxima ou superior a $10 \%$. Alguns subitens podem ser destacados, acompanhados pelas suas variações de preços: arroz, 13,19\%; feijão carioca, 26,62\%; batata, $66,47 \%$; tomate, $19,53 \%$; cebola, 94,72\%; cenoura, $52,73 \%$; alface, $12,1 \%$; laranja pera, $11,92 \%$.
A Tabela 5 foi construída levando em conta a variação de preços e a participação porcentual de cada item no IAD. Observa-se que os produtos in natura e minimamente processados continuam se destacando, mas duas fontes de proteína animal, leites e derivados e aves e ovos, aparecem, respectivamente, como terceiro e quinto itens que mais contribuíram para o IAD. Suas variações de preços não foram tão altas, mas eles têm grande participação porcentual nos gastos do consumidor ou na estrutura de ponderação do IPCA.

Tabela 5. Contribuição relativa de itens na alimentação no domićlio, em ordem decrescente, Brasil, janeiro a junho de 2020.

\begin{tabular}{lclc}
\hline \multicolumn{1}{c}{ Componente } & Variação & \multicolumn{1}{c}{ Componente } & Variação \\
\hline Tubérculos, raízes e legumes & 41,15 & Hortaliças e verduras & 4,23 \\
Cereais, leguminosas, oleaginosas & 18,76 & Farinhas, féculas e massas & 3,48 \\
Leites e derivados & 15,52 & Açúcares e derivados & 3,43 \\
Frutas & 11,87 & Oleos e gorduras & 2,88 \\
Aves e ovos & 8,96 & Carnes e peixes industrializados & 2,56 \\
Sal e condimentos & 8,15 & Pescados & 1,68 \\
Bebidas e infusões & 6,65 & Enlatados e conservas & 0,81 \\
Panificados & 5,00 & Carnes & $-5,13$ \\
\hline
\end{tabular}

Fonte: IBGE (2020) ${ }^{[1]}$.

Fica evidenciado que o item carnes, cujos preços haviam aumentado muito entre 2007 e 2019, foi o grande responsável pelo fato da inflação de alimentos não ser ainda maior no primeiro semestre 
de 2020. Entre todos, este é o item que tem maior participação no IAD, de 19,77\%, seguido por leites e derivados, panificados e bebidas e infusões, cada um com participação próxima a 11,60\%.

Avançando sobre as possíveis causas da manutenção da inflação de alimentos na primeira metade de 2020 no Brasil, convém avaliar o comportamento dos preços internacionais e da taxa de câmbio. O Gráfico 4 revela que os preços internacionais dos alimentos apresentaram expressiva queda no primeiro semestre de 2020, em decorrência da crise econômica derivada da Covid 19, resultando em diminuição do poder de compra e da demanda de alimentos. Ao mesmo tempo, aos moldes do verificado entre 2011 e 2019 , a variação da taxa de câmbio brasileira, caracterizada pela desvalorização do real perante o dólar, manteve-se como um item de pressão inflacionária no Brasil.

Gráfico 4. Índice Internacional de Preços de Alimentos da FAO e de Taxa de Câmbio (R \$ US\$), dezembro 2019 a junho 2020.

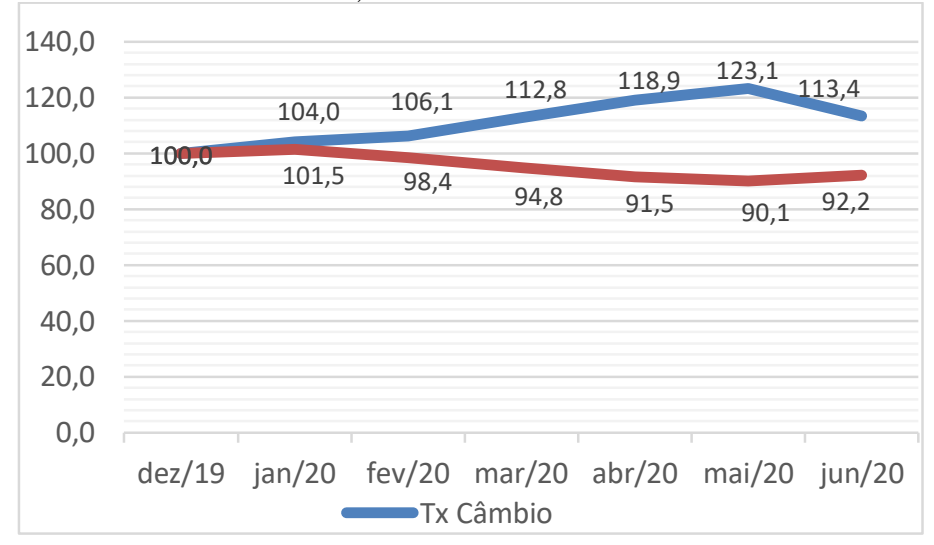

Fonte: FAO (2020)[5], IPEA (2020) ${ }^{[18]}$.

Entretanto, deve-se considerar que foram produtos sem ou com mercado externo pouco expressivo, arroz, feijão e FLV, que mais pressionaram a inflação no primeiro semestre de 2020. Aqui deve-se considerar que, embora a demanda por alimentação fora do domicílio tenha caído, a por alimentos no domićlio parece ter aumentado. Um fato que comprovaria tal hipótese é o crescimento real de 3,5\% nas vendas dos supermercados no Brasil, entre o primeiro semestre de 2019 e de 2020[21]. Gastos com produtos considerados não essenciais, lazer, viagem e transporte foram cortados, possibilitando maior direcionamento da renda para compra de alimentos. Além do mais, a vigência da renda de emergência por três meses, entre abril e junho de 2020, parece ter compensado grande parte da queda de renda do trabalho em função do aumento da taxa de desocupação.

Neste sentido, análise feita por técnico do IPEA, com base na Pesquisa Nacional por Amostra de Domicílios Covid-19 de julho de 2020, mostra que neste mês houve queda de $13 \%$ no rendimento médio efetivamente recebido em relação ao que seria habitualmente recebido pelo brasileiro. Contudo, ao se acrescentar o auferido através da renda de emergência, o rendimento de fato recebido pelo brasileiro ultrapassou em $1 \%$ o rendimento habitual; destacando-se o ocorrido nos domicílios com renda baixa, em que este aumento foi de $24 \%{ }^{[22]}$.

Produtos não comercializáveis têm a produção muito próxima da demanda interna. Se esta aumenta expressivamente, a resposta imediata é a elevação do preço agrícola ou da margem de comercialização, impactando nos preços aos consumidores. Isto pode ter sido agravado por retração na oferta de alguns produtos, afetada por dificuldades de suprimentos de insumos agrícolas ou pela queda da renda agrícola ou não das famílias de pequenos agricultores. Não foi possível levantar evidências quanto a esses pontos.

Como registram dados do Censo Agropecuário[23,24], com exceção do arroz, os demais produtos não comercializáveis, como feijão, mandioca e FLV, têm sua produção obtida majoritariamente em estabelecimentos de agricultores familiares. Algo semelhante acontece com frango, suíno e leite, que, contudo, apresentam mercado exterior significativo e são, em princípio, mais afetados por preços internacionais e pela taxa de câmbio.

Outra consideração importante é que o aumento dos preços de parte das FLV e do feijão pode ser momentâneo, posto que há possibilidades de se obterem várias safras durante o ano. No caso do arroz, a safra ocorre, praticamente, em um único momento do ano e só voltará a se repetir em 2021. Neste caso, apenas o aumento do volume importado tenderia a conter o preço interno durante 2020, mesmo porque não há como se socorrer em estoques 
reguladores, pois eles não existem em nível minimamente recomendável.

\section{CONSIDERAÇÕES FINAIS}

A inflação de alimentos no Brasil ocorreu, praticamente de forma contínua, de 2007 a 2019. Existem evidências de que isto se deveu mais à elevação dos preços ao produtor agrícola do que a acontecimentos na indústria alimentícia e nos canais de distribuição, em especial o varejo de alimentos.

A maior internacionalização da agricultura brasileira no presente século está associada ao fenômeno. Entre 2007 e 2011, ainda que a moeda nacional tenha se valorizado, os preços internos foram impactados pela elevação dos preços internacionais agrícolas. A partir de 2012, estes preços caíram suavemente, fato mais que compensado pela desvalorização do real perante o dólar, de forma que os preços internos continuaram aumentando.

Embora as condições do comércio exterior impactassem diretamente apenas os preços de produtos comercializáveis, não se descarta a hipótese de que, indiretamente, isto acabou por atingir também os não comercializáveis. Neste caso, entende-se que a adequação da oferta ao consumo nacional também deveria ser avaliada, para detectar pressões altistas mais localizadas. Tal avaliação fica como sugestão para próximos estudos.

A inflação de alimentos continuou se manifestando no Brasil no primeiro semestre de 2020, repetindo algumas e mostrando outras características. Se anteriormente era a alimentação fora do domicílio que apresentava maior aumento de preços, em 2020 o impacto maior veio da alimentação no domicílio.

Ao mesmo tempo, produtos in natura ou com baixo grau de processamento se sobressaíram como principal origem da inflação, como anteriormente, apontando a origem agrícola do processo. Contudo, os tipos de produtos in natura ou pouco processados se modificaram, ganhando importância no período mais recente FLV, arroz e feijão, em vez das carnes bovinas, do período anterior.
Entre as causas deste acontecimento, da persistência da inflação de alimentos em 2020, aponta-se a continuidade de desvalorização do real, compensando a queda dos preços internacionais agrícolas, que tendeu a se acentuar nesse ano. Neste ponto, sugere-se que sejam adotadas políticas públicas de controle do câmbio ou de taxação de exportação, protegendo mais os consumidores internos em detrimento dos interesses dos exportadores.

Além do mais, há evidências, como a elevação de vendas dos supermercados, apontando que a demanda por alimentos consumidos nos domicílios aumentou em 2020. Isto decorreu da transferência de gastos dos consumidores em favor dos alimentos e em detrimento de outros produtos e serviços, menos essenciais ou que tiveram seu consumo restringido por medidas sanitárias adotadas no enfrentamento da Covid 19. Também a instituição da renda emergencial atuou no sentido de elevar (ou evitar queda mais acentuada) o consumo de alimentos no Brasil.

Embora não tenha se apresentado evidências neste sentido, pode ter acorrido limitações conjunturais na oferta de alguns produtos agrícolas, justamente arroz, feijão e FLV. Neste caso, é possível que o aumento de seus preços estimule produtores, imediatamente, a elevarem suas decisões de produção, diminuindo as pressões altistas ao longo do tempo, para o feijão e algumas FLV mais rapidamente, para o arroz de forma mais demorada.

Ademais, seria muito importante que se adotassem políticas de estímulo à produção de produtos não comercializáveis ou com baixa presença no comércio externo. Entre elas, as que proporcionassem aumento de renda dos agricultores familiares, através de políticas de crédito rural e de compras institucionais, dando-lhes maior capacidade de investimento e gastos correntes. Nesta razão, deve-se levar em conta a ainda grande importância que a agricultura familiar apresenta na oferta de gêneros alimentícios. 


\section{REFERÊNCIAS}

[1] IBGE. Instituto Brasileiro de Geografia e Estatística. Índice de Preços ao Consumidor Amplo [Internet]. Rio de Janeiro; 2020. [acesso em 2020 set 20]. Disponível em: https://www.ibge.gov.br/estatisticas/economicas/preco s-e-custos/9256-indice-nacional-de-precos-aoconsumidor-amplo.html? $=\& \mathrm{t}=$ downloads

[2] Silva JG, Tavares L. Segurança alimentar e a alta dos preços dos alimentos: oportunidade e desafios. Segurança alimentar nutricional. 2008; 15(1): 62-75.

[3] IBGE. Instituto Brasileiro de Geografia e Estatística. Sistema Nacional de Índices de Preços ao Consumidor: estruturas de ponderação a partir da Pesquisa de Orçamentos Familiares 2002-2003. [Internet]. Rio de Janeiro; 2005. [acesso em 2020 fev 20]. Disponível em https://biblioteca.ibge.gov.br/index.php/bibliotecacatalogo?view $=$ detalhes\&id $=282203$

[4] IBGE. Instituto Brasileiro de Geografia e Estatística. Sistema Nacional de Índices de Preços ao Consumidor: estruturas de ponderação a partir da Pesquisa de Orçamentos Familiares 2008-2009. [Internet]. Rio de Janeiro; 2015. [acesso em 2020 fev 20]. Disponível em: https://www.ibge.gov.br

[5] FAO. Organização das Nações Unidas para Agricultura e Alimentação. Índice de preços de alimentos da FAO. [Internet]. Roma; 2020. [acesso em 2020 mai 10]. Disponível http://www.fao.org/worldfoodsituation/foodpricesinde $\mathrm{x} / \mathrm{en}$

[6] Mendonça de Barros JR, Rizzieri JAB, Picchetti P. Os efeitos da pesquisa agrícola para o consumidor. Relatório de Pesquisa. Fundação Instituto de Pesquisas Econômicas: São Paulo; 2001.

[7] Castro PF, Magalhães LCG de. Recebimento e dispêndio das famílias brasileiras: evidências recentes da Pesquisa de Orçamentos Familiares (POF) 1995-96. In: Silveira FG et al. (Orgs.). Gasto e consumo das famílias brasileiras contemporâneas. Brasília: IPEA; 2006. p. 21-69.

[8] Farina EMMQ, Nunes R. A evolução do sistema agroalimentar e a redução de preços para o consumidor: o efeito de atuação dos grandes compradores. Oficina. PENSA, estudo temático. 2002; 2(2):1-31.

[9] IBGE. Instituto Brasileiro de Geografia e Estatística. Pesquisa Nacional por Amostra de Domicílios Contínua Trimestral. [Internet]. Rio de Janeiro; 2020. [acesso em 2020 mai 12]. Disponível em: https://sidra.ibge.gov.br/pesquisa/pnadct/tabelas
[10] Hoffmann R. Estimativas das elasticidades-renda de várias categorias de despesas de consumo, especialmente alimentos, no Brasil, com base na POF de 2008-09. Rev. Economia Agrícola. 2010;57(2): 49-62.

[11] CONAB. Companhia Nacional de Abastecimento. Séries históricas das safras. [Internet]. Brasília; 2020. [acesso em 2020 fev 20]. Disponível em: https://www.conab.gov.br/info-agro/safras/seriehistorica-das-safras

[12] IBGE. Instituto Brasileiro de Geografia e Estatística. Pesquisa da Pecuária Municipal: primeiros resultados. [nternet]. Rio de Janeiro; 2018. [acesso em 2020 fev 20]. Disponível em: https://sidra.ibge.gov.br/pesquisa/ppm/quadros/brasil/ 2018

[13] Contini E. Exportações na dinâmica do agronegócio brasileiro - oportunidades econômicas e responsabilidade mundial. In: Buainain AM. et al. O mundo rural no Brasil do Século 21 - a formação de um novo padrão agrário e agrícola. Brasília (DF): EMBRAPA; 2014. p.147-173.

[14] FAO. Organização das Nações Unidas para Agricultura e Alimentação. FAO Statistical Yearbook 2010. [Internet]. Roma; 2011. [acesso em 2011 abr 10]. Disponível em: http:/ /www.fao.org

[15] Brasil. Ministério da Agricultura, Pecuária e Abastecimento. Estatísticas de comércio exterior. [Internet]. Brasília; 2020. [acesso em 2020 fev 2020]. Disponível

em: http://www.agricultura.gov.br/assuntos/relacoesinterna cionais/estatísticas-de-comercio-exterior

[16] IPEA. Instituto de Pesquisa Econômica Aplicada. A dinâmica da inflação brasileira: considerações a partir da desagregação do IPCA. Comunicado IPEA 101. Brasília: IPEA; 2011.

[17] Maluf R, Speranza J. Volatilidade dos preços internacionais e inflação de alimentos no Brasil: fatores determinantes e repercussões na segurança alimentar e nutricional. Brasília (DF): MDS/Secretaria de Segurança Alimentar e Nutricional; 2013.

[18] IPEA. Instituto de Pesquisa Econômica Aplicada. Taxa de câmbio - efetiva real - agricultura, pecuária e serviços relacionados. Ipeadata. Indicadores macroeconômicos. [Internet]. Brasília; 2020. [acesso em 2020 fev 20]. Disponível em: http//www.ipea.gov.br

[19] Baccarin JG, Bueno G, Silva DBP da. Cadeias e produtos agropecuários e a inflação brasileira da 
alimentação no domicílio. Rev. de Política Agrícola. 2015; 4(1):64-85.

[20] CEPAL/FAO. Comissão Econômica para América Latina e Caribe. Organização das Nações Unidas para Agricultura e Alimentação. Cómo evitar que la crisis del COVID-19 se transforme en una crisis alimentaria Acciones urgentes contra el hambre en América Latina y el Caribe. Informe COVID 19. CEPAL/FAO; 2020.

[21] ABRAS. Associação Brasileira de Supermercados. Índice de vendas do mês de junho 2020. [Internet]. São Paulo; 2020. [acesso em 2020 ago 12]. Disponível em: https://www.abras.com.br/economia-e-pesquisa/indicede-vendas/indice-do-mes

[22] Carvalho SS de. Os efeitos da pandemia sobre os rendimentos do trabalho e o impacto do auxílio emergencial: os resultados dos microdados da PNAD Covid-19 de julho. IPEA. Carta de Conjuntura. 2020;48(3):1-17.

[23] IBGE. Instituto Brasileiro de Geografia e Estatística. Censo Agropecuário 2006. [Internet]. Rio de Janeiro; 2021. [acesso em 2021 jan 28]. Disponível em: https://biblioteca.ibge.gov.br/visualizacao/periodicos / 5 1/agro_2006.pdf

[24] IBGE. Instituto Brasileiro de Geografia e Estatística. Censo Agropecuário 2017. [Internet]. Rio de Janeiro; 2021. [acesso em 2021 jan 28]. Disponível em: https://censos.ibge.gov.br/agro/2017/templates/censo_ agro/resultadosagro/index.html 